\title{
DESIGN AND IMPLEMENTATION OF A NETWORK LAB TO ENHANCE UNDERGRADUATE NETWORKING AND INFORMATION ASSURANCE CURRICULUM IN A BACCALAUREATE DEGREE PROGRAM: A CASE STUDY
}

\author{
Johnathan Yerby, Macon State College, Johnathan.Yerby@Maconstate.edu \\ Kevin Floyd, Macon State College, Kevin.Floyd@Maconstate.edu \\ Jacob Morrison, Undergrad Student Macon State College, Jacob.Morrison@Maconstate.edu
}

\begin{abstract}
The curriculum of a program in Information technology must be current and competitive to remain relevant and valuable. The authors of this paper explored the research related to the rationale to supplement higher education theoretical knowledge of networking and information assurance with opportunities for students in technology related programs to gains some hands-on experience. The paper also used the widely accepted learning theories of active learning and constructivism to assist in the decision to build the lab environment. An explanation of the processes, opportunities, challenges, and outcomes are available in the Lab Planning and Implementation sections. Finally the paper concludes with implications for students and recommendations for other higher education institutions that are considering enhancing theory with practical hands-on learning opportunities.
\end{abstract}

Keywords: Information Technology, Lab, Networking, Security, Constructivism, Experiential learning

\section{INTRODUCTION}

According to the Association for Computing Machinery (ACM) Information Technology curriculum guidelines, "Information Technology is a laboratory discipline" (2008)a successful information technology program must not only teach students soft skills, but also technical skills or skills in understanding and modeling organizational processes and data, defining and implementing technical and process solutions, managing projects, and integrating systems within and across organizations and focusing on the application of information technology in helping individuals, groups, and organizations achieve their goals (Topi et al., 2010). The IS 2010 model curriculum guidelines stated that appropriate lab facilities are needed to support project work (Topi et al., 2010). One area of the IT curriculum in which a combination of both theoretical and hands-on technical skills in a lab environment is needed is in the area of computer networking.

There is an increasing acceptance amongst academics on the value of supplementing theoretical knowledge with hands-on practical learning (Mengel\&Bowling, 1995; Cigas, 2002; Aravena\& Andres, 2009; Imboden\&Strothmann, 2010). Duffy and Jonassen (1992) explained in their book that a course curriculum can remain committed to theorybased instruction as a framework for thinking while simultaneously using a rich array of examples. Vygotsky's (1978) theory of social constructivism focused on the interaction of learners with others in cognitive development. Omrod (1995) stated that teachers could encourage students' development by presenting class exercises that students can complete only with assistance. The constructivist perspective encourages learning through interaction (Tam, 2000). Through use of a lab environment instructors are able to apply concepts recognized as 'constructivist teachers' including:

- assess students' understanding through application and performance of open-structured tasks;

- encourage and accept student autonomy and initiative;

- use a wide variety of materials, including raw data, primary sources, and interactive materials and encourage students to use them;

- inquire about students' understandings of concepts before sharing his/her own understanding of those concepts; 


\section{Issues in Information Systems \\ Volume 13, Issue 1, pp. 321-330, 2012}

- engage students in experiences that show contradictions to initial understandings and then encourage discussion;

- encourage student inquiry by asking thoughtful, open-ended questions and encourage students to ask questions to each other and seek elaboration of students' initial responses(Brooks \& Brooks, 1993).

Learning only theory or only concentrating on specific hands-on exercises applicable now has the potential to result in only partial understandings and biased understandings. Theory is better understood when it can be practiced or applied. Tools that are in use today can become obsolete or functions are modified; if a student only learns how to simply operate a specific piece of hardware or software without understanding the theory then the student would be unprepared when they are faced with a new or different version. Research by Floyd, Harrington, and Santiago (2009) suggested that when IT students exposed to active learning assignments, including hands-on lab exercises, student cognitive engagement or the integration and utilization of students' motivations and strategies in the course of their learning increased. Students are able to learn the intricate theory of network related concepts and then apply the concepts in the learning lab.

The ACM curriculum guideline lists computer networking as one of the thirteen knowledge areas in their recommended four year curriculum (2008). Yet, Yaun and Zhong (2009) explained that computer networking is one of the most challenging subjects to learn and to teach in an efficient way. Most IT instructors still primarily use lectures as the exclusive means to teach. Imboden and Strothmann (2010) noted that while there are countless textbooks, web resources, and study guides, and tools such as Ping and Traceroute aimed at teaching networking concepts and providing hands-on experience, students often perceive the resources as dry and limited in their ability to teach and demonstrate application level consequences and effects to network changes. One approach to addressing this problem is to engage students by increasing real-world and hands-on learning activities within the IT networking curriculum.

The addition of the hands-on projects to enhance technical skills will only strengthen a student's ability to apply academic skills needed for an increasingly sophisticated workplace and society (Daggett, 2010). Ferreira agrees that technology is becoming embedded in academic life through introducing emerging technologies, course content acquisition, self-assessments, web searches and discussions through a myriad of communication technology (2010). Research (e.g., Imboden \&Strothmann, 2010; Yaun \& Zhong, 2009;Kouznetsova, 2008) indicated that there is a growing number of hands-on networking labs being created to supplement the theoretical concepts covered in undergraduate computer networking instruction. In this paper, the authors discuss design and implementation of a network lab for undergraduate students in networking. The network lab design is guided by one of most commonly used instructional design models, the Dick and Carey Systems Approach Model. According to the model, components such as the instructor, learners, materials, instructional activities, delivery system, and learning and performance environments interact with each other and work together to bring about the desired student learning outcomes (2009). The hands-on networking lab is designed to supplement theoretical concepts and provides the instructional activities, delivery system, and learning environment to enable students to configure, maintain and troubleshoot network hardware and software. The instructor serves as a facilitator within the lab environment. The instructor interacts with the students in the lab environment to ensure learning outcomes are met.

\section{LAB DESIGN AND IMPLEMENTATION}

The School of Information Technology at Macon State College requires all students to complete a senior capstone course as part of the requirements for the Bachelor of Science in Information Technology degree. As part of the course, students work in teams to develop a significant project (Koohang, Floyd, Spiers, Riley, 2009). One of the groups consisted of ten networking students tasked with the project of planning, designing, implementing, and testing a fully operational, dynamic, and forward reaching network lab. The lab would be the first of its kind at Macon State College. The group of students elected a project manager. The project manager worked with the students and two faculty advisors. The School of IT provided an initial budget of $\$ 2,000.00$. Having the students take onus for the lab was a benefit in the following ways: 


\section{Issues in Information Systems}

Volume 13, Issue 1, pp. 321-330, 2012

- It afforded the opportunity for soon-to-be-graduates to employ an array of project management, systems analysis, and networking technical skills garnered over their academic career.

- Soon to be graduates heralded a unique insight as to what portions of the curriculum they would have liked to have seen explored with a more hands-on learning approach.

- Student buy-in for the project was immediate and immense. The lab was a chance for this group of 10 students to leave a lasting contribution for years to come.

The group began its efforts with a visit to a nearby technical college with an established networking lab. The goal of this visit was not to simply copy the current infrastructure, but rather to establish its capabilities and discover any best practices. The capstone group toured four separate networking labs tailored for various level of complexity and spoke at length with several IT instructors about how the labs are utilized. A wealth of information was gathered during this initiative but one of the most influential was the discovery of a networking lab manual [Networking Fundamentals, 2nd Edition Laboratory Manual By: Richard M. Roberts ISBN: 978-1-60525-358-9 Copyright: (02012] containing over 100 network lab activities. The group examined the lab manual in great detail and identified 63 activities they felt would enhance the current IT curriculum offerings at Macon State College. These activities were translated into a desired list of capabilities which set the foundation for the initial design of the lab.

The School of Information Technology was able to secure a dedicated classroom consisting of 32 student computers, 1 instructor PC with attached projector, smart board, and a large storage closet (see Figure 1). The existing room was already fully wired and apart of the Macon State College network. A major part of this project would involve re-wiring the classroom to place it on its own isolated network, separated from the College's network.

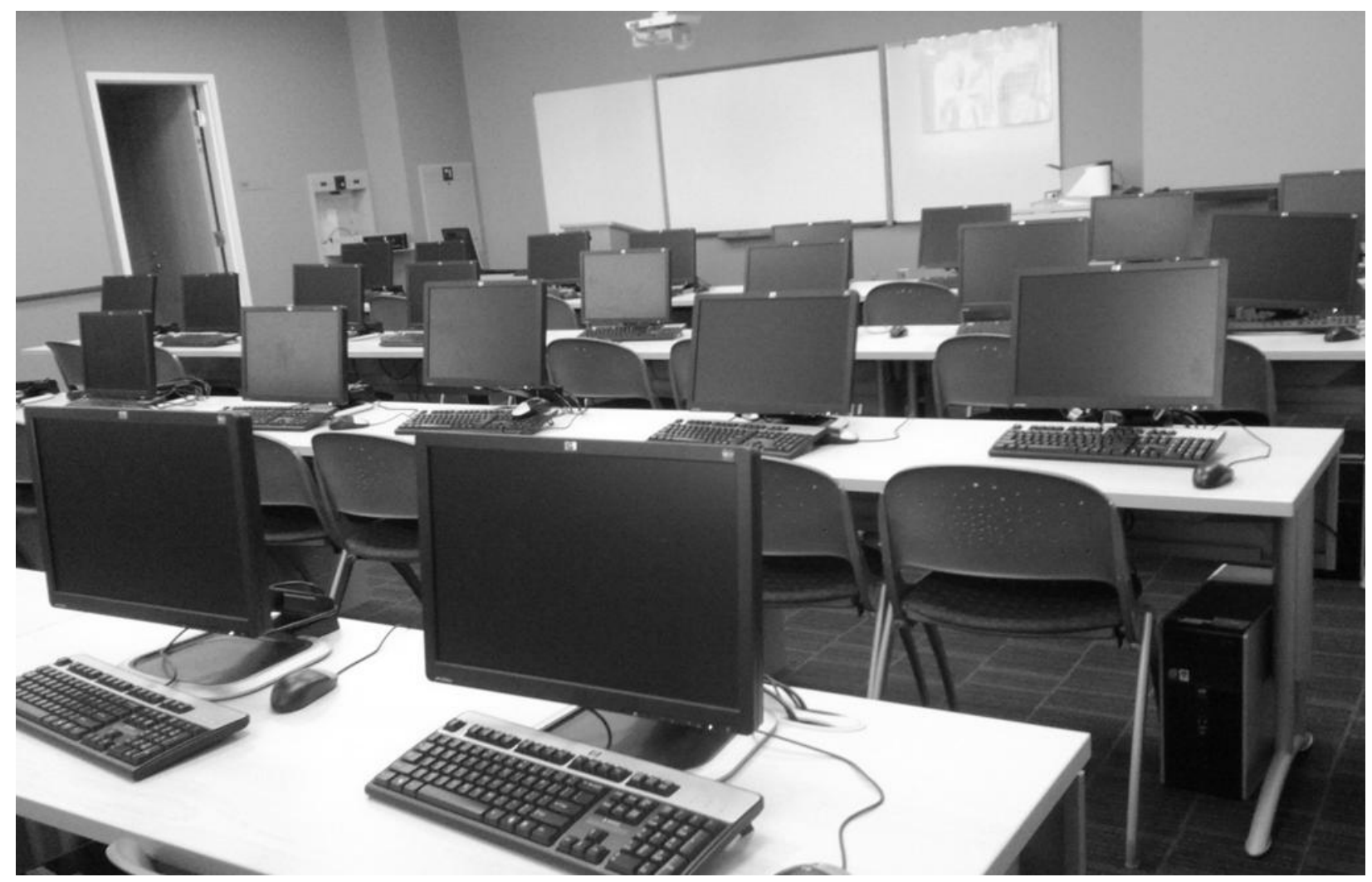

Figure 1. School of Information Technology Lab 


\section{Issues in Information Systems \\ Volume 13, Issue 1, pp. 321-330, 2012}

During the planning phase the group determined that the lab would also need a high-speed connection to provide internet connectivity. After discussions with the College's Technology Resources staff, it was decided that the lab would be provided with its own direct $10 \mathrm{mbps}$ fiber connection with Peachnet, the statewide communications network supporting all University System of Georgia (USG) Information Technology Services. Since the infrastructure to connect to the Peachnet circuit was already in place, no additional fees were incurred to establish the connection.

The computers in the classroom were already connected to the existing school network. The decision for the network lab to be completely segregated from the existing college network required a creative solution for cabling. The initial option was to directly connect the lab PCs to a patch panel and then a switch in the classroom network closet. Choosing this option would involve creating and installing new Cat6 cables to all PCs, terminate the cable at the end of each row, and routed up specially installed conduit. The conduit would take the cables into the classroom ceiling and the cabling would then be run through the ceiling over into the classroom network closet. Directly connecting the PCs to the classroom network closet would have been significantly less expensive, but this option did not conform to all of the structured cabling requirements outlined in ANSI/TIA/EIA 568 standards and the college's classroom design standards.

After ruling out the option of installing new Cat6 cable to connect the classroom directly to the networking closet, the group formed a new plan. The new plan would take advantage of the existing infrastructure in the building and classroom. The cabling that was already in place was not changed in the classroom or through the floors and walls. The PCs in the lab connect to a network closet located about 100 feet down the hallway. On the original configuration the PCs cable connections terminated into a college network patch panel and then to a college network switch. The new design to segregate traffic cut the connection to the college network. Two new patch panels were installed. The cables coming from the network lab terminate into patch panel 2 (see Figure 2) and then the cables are connected to patch panel 1 . Patch panel 1 brings the connection back down the hallway to the networking closet and connects to patch panel 3. Patch panel 3 can connect to any of the three switches in the network laboratory rack. This design allowed flexibility in the event that the college had to revert back to having the laboratory function as a regular classroom on the college network. If the lab needs to be reverted back to a normal classroom then cables only have to be moved from patch panel 2 to the original college network patch panel. For connections to get out to the internet, one of the ports on patch panel 2 is connected to a media converter that is bringing in a fiber connection from Peachnet. The fiber runs across the campus from the Library where it connects to the Peachnet network, through a fiber switch in the Library, then fiber connects to the Professional Science Building Network closet on the first floor a fiber switch, then the connection runs as fiber to the second floor where it eventually connects back to the media converter. For the PCs in the lab to communicate with each other they are connected to one of the Cisco 3500XL switches in the laboratory network closet. The first switch in the rack is dedicated for when students need access to the internet. The second switch is dedicated to working offline but still connected to peers in the network. The third switch is in place for future use of advance switch configuration. Cabling was the most expensive component of this lab. The price for professional cable installation was $\$ 8,197.00$, far exceeding the initial $\$ 2,000.00$ budget. Fortunately, the Provost's Office agreed to cover the cabling expenses, putting the project back under budget. 


\section{Issues in Information Systems}

Volume 13, Issue 1, pp. 321-330, 2012

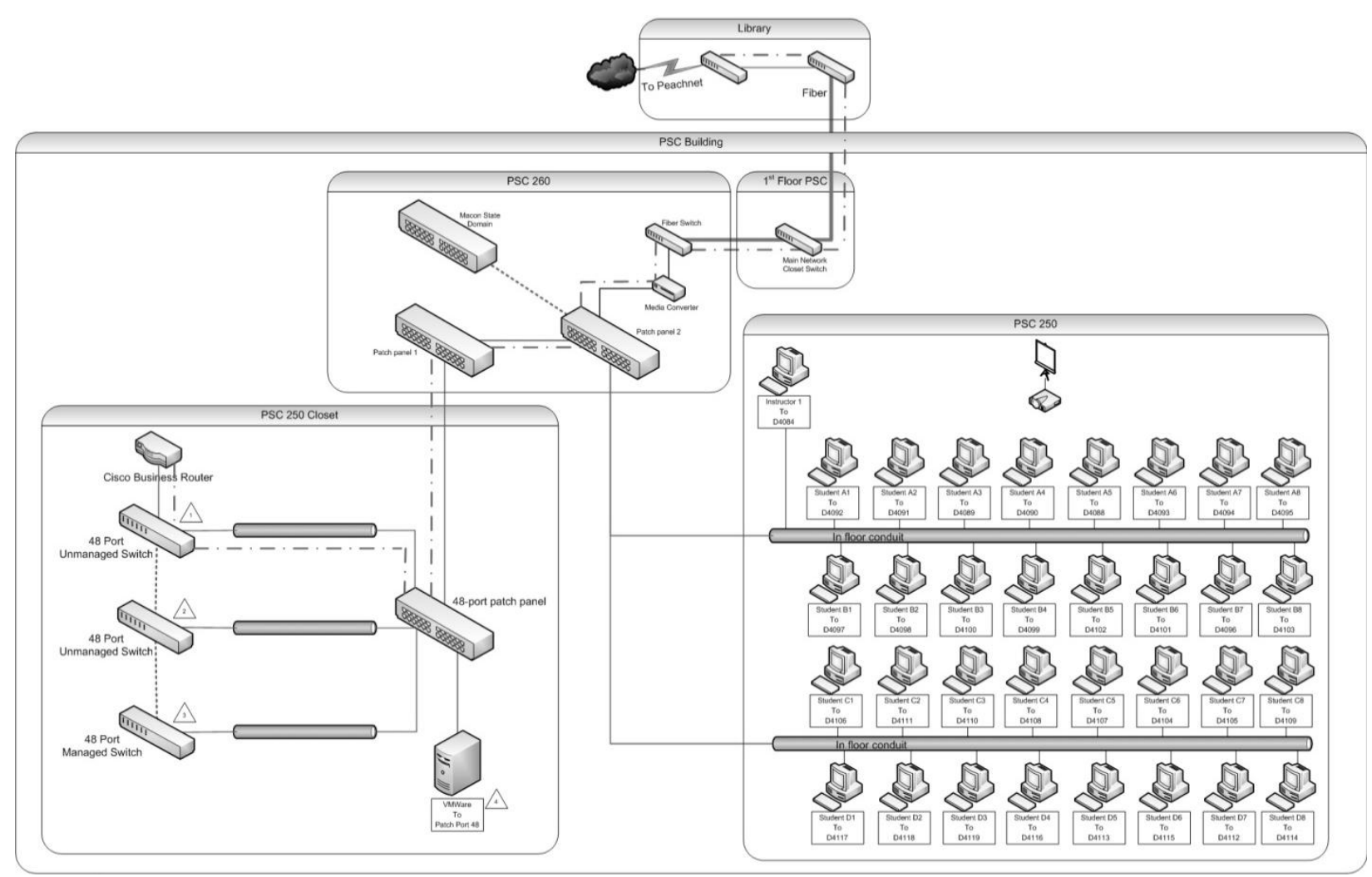

Figure 2.Complete Network Diagram

After the cabling issues were addressed, the installation and configuration of specific network equipment began. Two of the students on the team were also employees at a local Technical College that agreed to donate 3 Cisco Catalyst 3500 Series 10/100 48-port network switches. The other major hardware included two existing servers, patch panels, VMware Hypervisor, and power strips. A detailed rack design was approved as shown in Figure 3. Two 19-inch racks weremounted by the college's physical plant department with attention to classroom and OSHA safety standards. An additional horizontal brace was installed to provide additional stability. Each individual rackmount component was installed in accordance with the finalized rack diagram in Figure 4. Ninety-six patch cables were hand built by team members to facilitate lab connectivity between the patch panel and the various switches. Initial design specifications demanded that the internet connectivity via ISP Peachnet not be interfered with by lab activities. The top switch is to be dedicated to connecting the class to the router, and then to the internet and this switch is not to be utilized for any form of lab activity except at the discretion of the instructor. Various lab activities, especially the Hypervisor dependent on its configuration can interfere with the router and prevent normal access. Lab activities are limited to switches \#2 and \#3. As a measure to ensure that lab activities do not have accidentally connect to the wrong switch, patch cables were cut at specific lengths which prevents switch \#1 from being accessed by switches \#2 and \#3. Additionally, patch cables were color coded to further emphasize the lab practice connection versus a live connection to Peachnet. The VMware Hypervisor was the constructed and patched into the patch panel. 


\section{Issues in Information Systems}

Volume 13, Issue 1, pp. 321-330, 2012

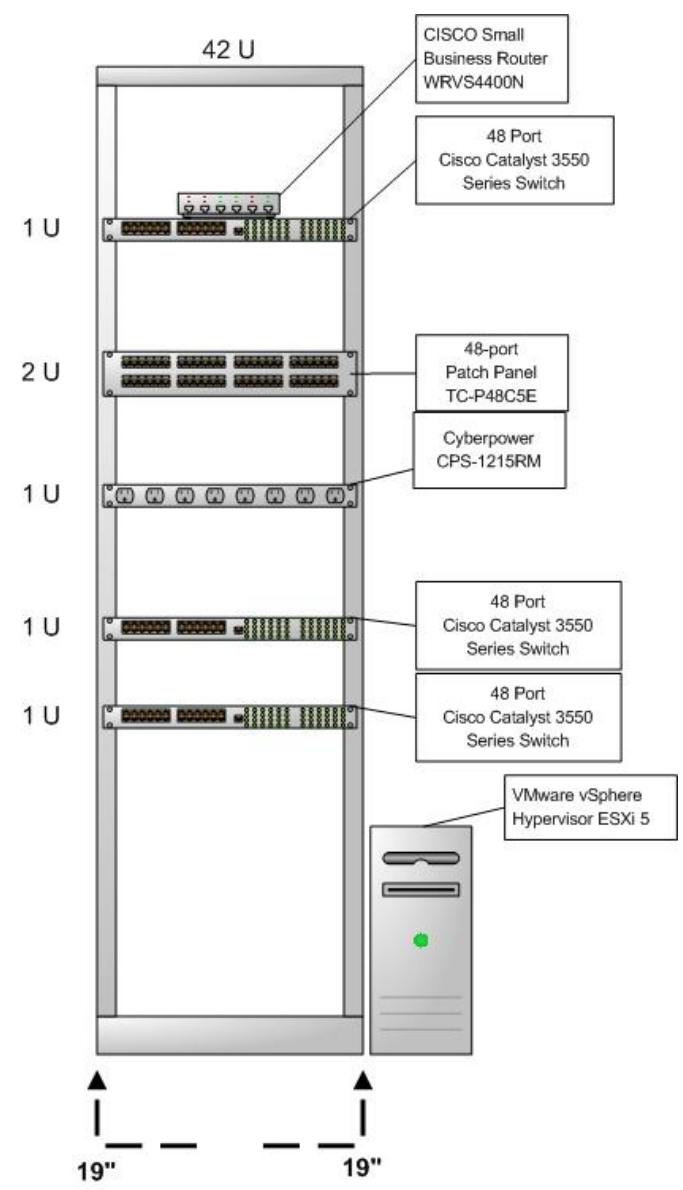

Figure 3.Networking rack plan

Based on the activities requirements and desired capabilities a rack design was created. The diagram incorporated three switches, a patch panel, two rack mounted power strips, the VMware Hypervisor (running ESXi 5), and a dedicated connection to an independent internet line provided by ISP Peachnet. The VMware Hypervisor was created with the capability to simultaneously run the host operating system of Windows 7 plus four virtual machines in the VMware environment. The hard drive storage space is capable of storing more than 40 separate operating systems installations. Table 1 details the complete costs to build this networking lab at a cost of $\$ 9,550$. The price for the networking equipment was $\$ 1353$. The low cost was achieved through diligent research of required components, some of the components were on sale at the time of purchase, and three of our network switches were donated from a community partner. Three 48 port switches could have been purchased for under $\$ 500$, which would still keep the total cost of equipment under $\$ 2000$. As previously mentioned the cost of cable installation was by far the most expensive component at $\$ 8,197$. 


\section{Issues in Information Systems \\ Volume 13, Issue 1, pp. 321-330, 2012}

\begin{tabular}{|c|c|c|}
\hline Quantity & Description & Cost \\
\hline 1 & Intel Xeon E3-1230 3.2 GHz LGA Quad-Core Server Processor & 239.99 \\
\hline 1 & Rack Screws & 3.95 \\
\hline 1 & Sony DVD-Rom Drive & 23.99 \\
\hline 1 & RackmountPowerstrip & 39.99 \\
\hline 1 & Kingston 8GB 240-Pin DDR3 SDRAM Server Memory & 69.99 \\
\hline 1 & Antec NSK Black / Silver Computer Case & 89.99 \\
\hline 2 & Hitachi 500GB 3.5 SATA $3.0 \mathrm{~Gb} / \mathrm{s}$ Hard drive & 319.96 \\
\hline 1 & Cisco Linksys WRVS4400N Wireless Gigabit Router & 174.95 \\
\hline 1 & ASUS P8B-X ATX Server Motherboard & 189.99 \\
\hline \multirow[t]{2}{*}{1} & Siemens HD6 Patch panel & 200.00 \\
\hline & Total Hardware Cost: & $\$ 1,352.80$ \\
\hline \multirow{3}{*}{3} & Professional Cable Installation & $\$ 8,197.00$ \\
\hline & Cisco Catalyst 3500 Series 10/100 48-Port Network Switch & Donated \\
\hline & Total C & $\$ 9,549.80$ \\
\hline
\end{tabular}

Table 1.Network Equipment Cost

After reviewing the curriculum of other IT courses, the group concluded that it was not a lack of network hardware that was limiting the labs potential, but rather a lack of software offerings. Many of the courses required a myriad of Operating Systems and various software configurations. To address the needs of so many disparate courses it was quickly realized that the ability to provide every OS from any platform (Windows, Linux, OSX, etc.) would be required. Initial research quickly revealed that some form of virtualization would be required to realize this goal. A review of the literature showed that "in the past few years, a number of IT educators have begun to explore how to enhance their teaching using virtual servers" (Wagner \&Pant, 2010). Stackpole (2008) stated, "the current physical teaching laboratory has been proven effective... however there are still a number of opportunities for improvement." Virtualization introduces those improvements in forms of reduced costs, additional capabilities, increased performance, and flexibility to suit multiple environments. The ability of virtualization to "increase laboratory utilization [and] student productivity" seemed to be in line with the project's extended goals (Stackpole, Koppe, Haskell, Guay, \& Pan, 2008).

The group considered a variety of virtualization platforms including Microsoft Virtual PC, Microsoft Hyper-V Server, and VMware vSphere Hypervisor ${ }^{\mathrm{TM}}$ (ESXi 5). The findings suggested that "the Virtual PC environment did not provide sufficient control over the network to allow a direct translation of lab exercises targeted" (Stackpole, 2008). Hyper-V was found to be overly complex and required several other windows-based components to be running in concert to realize its full potential. "VMware offered the most guest operating system support, the highest cross-platform compatibility", was capable of running on minimal hardware, and required no software purchase (Stackpole et al., 2008). An undergraduate network lab should not limit students to one vendor's practices. The advantages provided by a VMware-based solution outweighed this shortcoming. The focus is in providing the ability for the lab to host any guest Operating System required by the instructor. This, combined with the fact that "VMware was one of the originators of the Type 2 server virtualization software and is currently the market leader" led the group to accept the decision to utilize only one virtualization solution (Wagner \&Pant, 2010). Additionally, the snapshot capabilities provided by VMware are more robust than its competitors. This permits instructors or students to "save" a working and known-condition instance of a client OS. Instructors can then feel free to explore avenues that might lead to "breaking" the OS with the ability to rapidly return to a previous state. Students do not have to be concerned about the time involved with a complete reload if they make a drastic configuration mistake; they can simply revert to a previous snapshot and attempt a lab procedure again. 


\section{Issues in Information Systems}

Volume 13, Issue 1, pp. 321-330, 2012

Testing of the lab was accomplished by first loading the VMware Hypervisor with a guest OS. The group started by loading Windows Server 2008 R2 which ran successfully. This ensured the VMware components had been installed properly and that the system was operating correctly. Next, all CISCO switches were reset to factory settings and all ports were turned on to active. Individual student desktops were then posted, and static ping commands sent to the Windows Server 2008 R2 client OS. Successful pings ensured that the student desktops, switch ports, and associated patch panels and cabling were operating within desired parameters. This testing scenario was repeated on all three switches. Finally, the CISCO router was consoled into and setup for Dynamic IP assignment and then connected to switch \#1 along with all desktops. All desktops successfully received an IP from the router. The completed network rack matched the initial design and can be viewed in Figure 3 below.

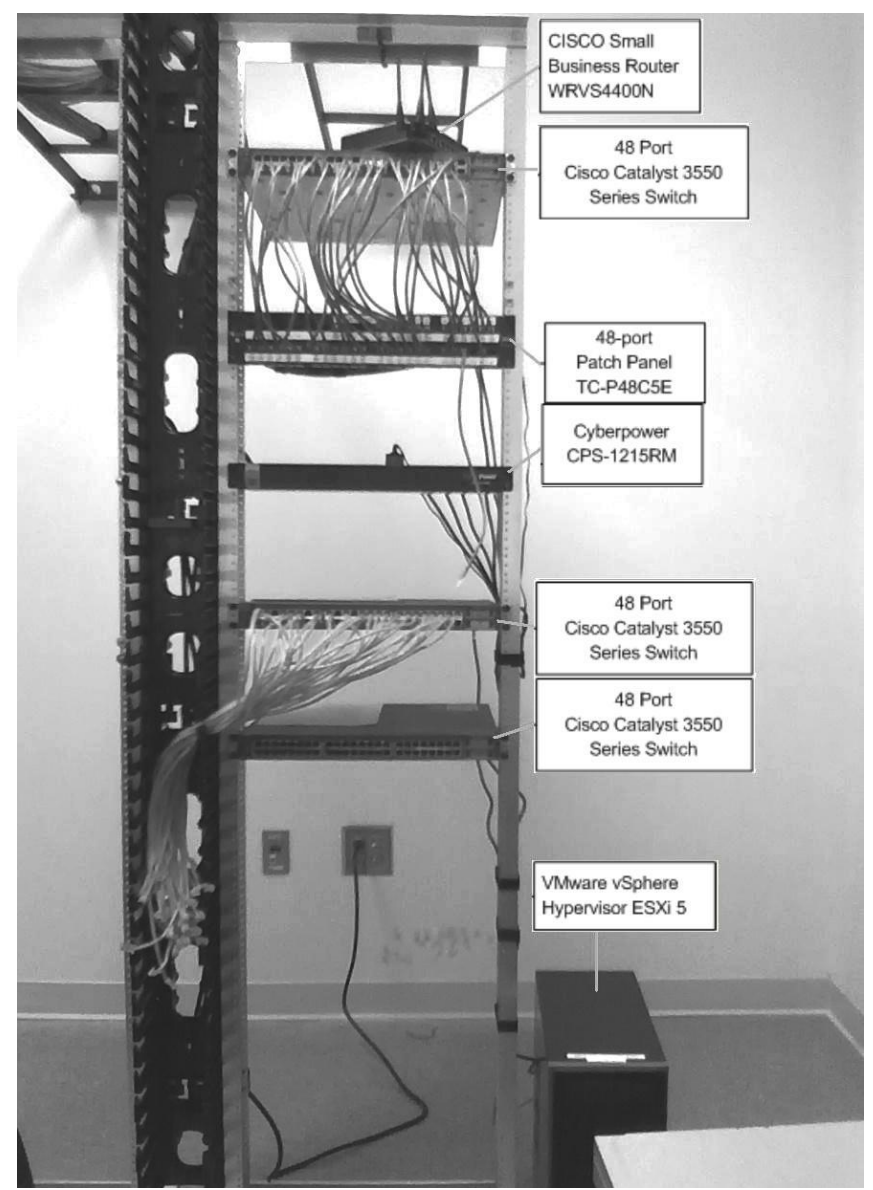

Figure 4. Completed network rack

\section{CONCLUSIONS}

The decision to build a networking lab was motivated by the need to supplement theoretical concepts with hands-on learning activities and to give students experiences similar to those likely to be encountered in the work force. Historically, teaching in a college or university program has placed heavy emphasis on theoretical learning and very little on hands-on or experiential learning. Research showed that critical learning related to the field of networking is enriched with the addition of a laboratory (e.g., Imboden\&Strothmann, 2010; Yuan \& Zhong, 2009; Kouznetsova, 2008). This paper presented the steps involved in the design, develop, and implementation ofa low cost network lab by a group of senior capstone students. While there were many planning and budgetary challenges, we were able to turn these into learning experiences for the students involved. The experience demonstrates that an effective handson networking laboratory is feasible, even with very limited resources.Following strict project management 


\section{Issues in Information Systems \\ Volume 13, Issue 1, pp. 321-330, 2012}

methodology and maintaining constant feedback was imperative to keeping the project as a success. Along the way there were chances for some of the team to make a mistake, but constant accountability prevented any failures or setbacks. Support from the Provost of the college, Dean of the School of IT, the CIO of the campus network, technical assistance from the University System, top student leaders, and faculty members was critical for success of the project. The lab can be used in several courses including: Introduction to Information Technology, Networking Essentials, Windows Systems Administration, Linux System Administration, Web Server Administration, Digital Forensics and Data Recovery, Wireless Technologies, Data Communications, and Network Security. The flexible, scalable, and enduring design of the laboratory was carefully planned to ensure such a wide array of courses could benefit from this new tool now and for several years ahead.

The group of 10 students in the Senior Capstone Networking team was extremely satisfied with their experience. The students commented that they were able to use skills gained from several courses that they have taken over their entire academic career. Some students mentioned that the experience was one of the most positive things that they have done in their life. The students seemed very proud. Two weeks after the project completion a ribbon cutting ceremony was held where students and faculty across the campus attended to explore the new lab and see demonstrations. Some of the project team members invited their parents to show off the newly created lab. During the ribbon cutting ceremony some students that were graduating indicated that they wish that they were not graduating yet because they want to experiment in the networking lab. Students using the lab were pleased to be able to use information assurance software that was previously unavailable due to potential threat to the campus network. The lab also grants students the ability to explore the entire network, create problems, and understand the reasoning of networking concepts.

\section{REFERENCES}

1. ACM. (2008). Information technology 2008: Curriculum guidelines for undergraduate degree programs in information technology. http://www.acm.org/education/curricula/IT2008\%20Curriculum.pdf

2. Aravena M, \& Andres, R. (2009). Use of a remote network lab as an aid to support teaching computer. CLEI Electronic Journal, 12(1), 8.

3. Brooks, J. G. and Brooks, M. G. (1993). In search of understanding: the case for constructivist classrooms, Alexandria, VA: American Society for Curriculum Development.

4. Cigas, J. (2002). A computer networking laboratory for administration and networking. Frontiers in Education, 1(T3D), 12-11.

5. Daggett, W. (2010). Preparing students for their technological future. International Center for Leadership in Education, Retrieved from http://www.leadered.com/pdf/Preparing Students for Tech Future white paper.pdf

6. Dick, W., Carey, L., \& Carey, J. (2009). Systematic design of instruction. (7 ed.). Boston, MA: Allyn \& Bacon.

7. Duffy, T. M., \&Jonassen, D. H. (1992). Constructivism and the technology of instruction: a conversation. (Thomas M Duffy \& David H Jonassen, Eds.)Computers in Human Behavior (Vol. In Press, p. 221). Lawrence Erlbaum Associates. Retrieved from http://books.google.com/books?id=7Uv8NHvKK44C

8. Ferreira, M. J. M. (2010). Intelligent classrooms and smart software: Teaching and learning in today’s university. Education and Information Technologies, 1-23. Springer Netherlands. Retrieved from http://www.springerlink.com/index/10.1007/s10639-010-9134-8

9. Floyd, K. S., Harrington, S. J., \& Santiago, J. (2009). Improving I.S. student engagement and perceived course value.Proceedings of the 2009 Southern Association for Information Systems Conference, 24-29.

10. Imboden, T., \& Strothmann, D. (2010). Design and implementation of a low-cost networking and voip lab for undergraduate networking curriculum instruction. Issues in Information Systems, 11(2), 1-6. Retrieved from http://iacis.org/iis/2010/1-6_LV2010_1433.pdf

11. Koohang, A., Floyd, K., Spiers, R., \& Riley, E. (2009). Design, implementation, and assessment of an information technology senior capstone course. Issues in Information Systems, X(1), 22-27.

12. Kouznetsova, S. (2008). A networking lab facility on the cheap: turning obstacles into opportunities. Journal of Computing Sciences in Colleges, 23(4), 180-185. 


\section{Issues in Information Systems}

Volume 13, Issue 1, pp. 321-330, 2012

13. Mengel, S. A., \& Bowling, C. D. (1995). Supporting networking courses with a hands-on laboratory. Frontiers in Education Conference, 1995. Proceedings., 1995 (Vol. 2, p. 4c2.20-4c2.23 vol.2). Presented at the Frontiers in Education Conference, 1995. Proceedings., 1995. doi:10.1109/FIE.1995.483214

14. Omrod, J. (1995). Educational Psychology: principles and applications, Englewood Cliffs, NJ: Prentice Hall.

15. Stackpole, B. (2008). The evolution of a virtualized laboratory environment. Proceedings of the 9th ACM SIGITE Conference on Information Technology Education, 243-247.

16. Stackpole, B., Koppe, J., Haskel, T., Guay, L., \& Pan, Y. (2008). Decentralized virtualization in systems administration education. Proceedings of the $9^{\text {th }}$ ACM SIGITE Conference on Information Technology Education, 249-254.

17. Tam, M. (2000). Constructivism, instructional design, and technology: Implications for transforming distance learning.Educational Technology \& Society,3(2), Retrieved from http://www.ifets.info/journals/3 2/tam.html

18. Topi, H., Valacich, J.S., Wright, R.T., Kaiser, K.M., Nunamaker, J.F., Sipior, J.C., \& de Vreede, G. (2010). IS 2010: Curriculum guidelines for undergraduate programs in information systems. Communications of the Association for Information Systems, 26(18), 359-428.

19. Vygotsky, L.S. (1978). Mind and society: The development of higher mental processes. Cambridge, MA: Harvard University Press.

20. Wagner, W.P., \& Pant, V. (2010). Using virtual servers to teach the implementation of enterprise-level dbmss: A teaching note. Journal of Information Systems Education, 21(4), 349-352.

21. Yuan, D., \& Zhong, J. (2009). An instructional design of open source networking laboratory andcurriculum. Proceedings of the 10 ${ }^{\text {th }}$ ACM SIGIT Conference on Information Technology Education, 37-42. 